\title{
Adsorption studies of methylene blue and gentian violet on sugarcane bagasse modified with EDTA dianhydride (EDTAD) in aqueous solutions: Kinetic and equilibrium aspects
}

\section{Karla Aparecida Guimarães Gusmão, Leandro Vinícius Alves Gurgel, Tânia Márcia Sacramento Melo, Laurent Frédéric Gil*}

Grupo de Química Orgânica e Ambiental, Departamento de Química, Instituto de Ciências Exatas e Biológicas, Universidade Federal de Ouro Preto,

Campus Universitário Morro do Cruzeiro, 35400-000 Ouro Preto, Minas Gerais, Brazil

\section{A R T I C L E I N F O}

\section{Article history:}

Received 26 June 2012

Received in revised form

19 December 2012

Accepted 17 January 2013

Available online 21 February 2013

\section{Keywords:}

Adsorption

Methylene blue

Gentian violet

Modified sugarcane bagasse

EDTA dianhydride

\begin{abstract}
A B S T R A C T
In this study the adsorption of cationic dyes by modified sugarcane bagasse with EDTA dianhydride (EB) was examined using methylene blue (MB) and gentian violet (GV) as model compounds in aqueous single solutions. The synthesized adsorbent (EB) was characterized by FTIR, elemental analysis, and BET. The capacity of EB to adsorb dyes was evaluated at different contact times, $\mathrm{pH}$ values, and initial dye concentrations. According to the obtained results, the adsorption processes could be described by a pseudo-second-order kinetic model. The adsorption isotherms were well fitted by the Langmuir model. Maximum adsorption capacities for MB and GV on EB were found to be 202.43 and $327.83 \mathrm{mg} / \mathrm{g}$, respectively. The free energy change during adsorption of $\mathrm{MB}$ and $\mathrm{GV}$ was found to be -22.50 and $-24.21 \mathrm{~kJ} / \mathrm{mol}$, respectively, suggesting that chemisorption is the main mechanism controlling the adsorption process.
\end{abstract}

(c) 2013 Elsevier Ltd. All rights reserved.

\section{Introduction}

Synthetic dyes have been extensively applied to many technological fields including the textile industry, leather tanning, paper production, food technology, in photo electrochemical cells, and also for hair coloring products (Forgacs et al., 2004). It is estimated that the amount of synthetic dyes produced worldwide is greater than 10,000 tons per year. Due to the large-scale production of synthetic dyes and their extensive application, they can cause considerable environmental pollution and pose a serious risk to public health (Forgacs et al., 2004).

The effluent discarded by the textile industry causes several problems to the environment due to the presence of a wide range of contaminants such as acids, bases, dissolved solids, and dyes. Amongst all these contaminants, the dyes are probably the most undesirable, since they are non-degradable toxic substances and tend to be quite stable for long periods of time (Gupta et al., 2004). Color changes resulting from the presence of these dyes interfere

\footnotetext{
* Corresponding author. Tel.: +55 313559 1717; fax: +55 3135591707

E-mail address: laurent@iceb.ufop.br (L.F. Gil).
}

with the penetration of solar light in aquatic environments and prevent photosynthesis, thus inhibiting the growth of aquatic biota and also interfering with the solubility of gases in bodies of water. Moreover, direct discharges of synthetic dyes into urban wastewaters in natural environments may cause the formation of toxic carcinogenic breakdown products (Garg et al., 2004).

Due to its commercial and social importance, the impact and toxicity of major dyes released into the environment have been widely studied. Methylene blue dye (MB) is most commonly used in cotton, wood, and silk. It causes a sensation of burning in the eyes and eventually results in permanent damage. Ingestion also produces a burning sensation and can cause nausea, vomiting, deep sweating, mental confusion, and methemoglobinemia (high levels of methemoglobin in the blood), while inhalation causes irregular and rapid breathing after a short period of time (Ahmad et al., 2009). Gentian violet dye (GV) is also very harmful through inhalation, intake, and when it is in direct contact with the skin, causing cancer and severe eye irritation in human beings (Ahmad et al., 2009).

Several methods have been tested to remove color from industrial effluents with the goal of lessening their impact on the environment. Examples include adsorption on organic or inorganic matrices, discoloration by photo-catalysis or photo-oxidation 
processes, microbial degradation, chemical oxidation, ozonation, and coagulation (Gupta et al., 2004; Sun and Yang, 2003).

Adsorption is one of the most effective processes used in dye removal; the most popular absorbent for this task is activated carbon, which is very effective due to its high surface area, microporous structure, and high adsorption capacity. However, the application of activated carbon on a large scale as an absorbent elevates the overall costs of the process considerably, making it economically unfeasible. Obviously, the additional expenses presented by the use of adsorption methods to remove dyes from effluents can be reduced if the adsorbent used is very cheap (Forgacs et al., 2004; Lata et al., 2008).

In recent years, extensive research has been undertaken to develop alternative and economically more attractive adsorbents. Recently, many low cost adsorbents from agricultural wastes and natural materials have been investigated for the removal of dyes from aqueous solutions (Hameed, 2009; Hameed et al., 2009). Sugarcane bagasse is a residue from the sugarcane crushing process, composed of macromolecules such as lignin (Xiao et al., 2001), polyoses and cellulose (Navarro et al., 1996). These macromolecules, through their hydroxyl groups, are able to react chemically to produce new adsorbent materials with new adsorption proprieties. Studies toward the application of sugarcane bagasse as an adsorbent material for a variety of pollutants can be found in the literatures (Ho et al., 2005; Karnitz et al., 2007; Pereira et al., 2009; Xing and Deng, 2009).

The synthetic route employed to prepare an adsorbent material is determined by the types of functional groups available on the solid support surface and the pollutant that is to be removed from the wastewater. Another important point is the cost of the solid support and the chemicals used in the synthesis of the adsorbent material. For new adsorbent materials to be considered attractive alternatives to those currently available, they should offer the advantage of low cost of production and maximum efficiency for the removal of a variety of pollutants from wastewaters. In addition, the recent concept of green chemistry requires that both solid support and chemicals can be recycled. In this regard, our research group has studied sugarcane bagasse, an important Brazilian agricultural by-product, as a solid support when derivatized with reagents such as succinic and EDTA anhydrides (Gurgel et al., 2008; Gusmao et al., 2012; Karnitz et al., 2007; Pereira et al., 2009). Estimated prices of sugarcane bagasse and EDTA disodium based on the current Brazilian market at this present time are approximately US $\$ 0.015 / \mathrm{kg}$ and US $\$ 12.64 / \mathrm{kg}$, respectively. These values are compatible with the concept of production of a low cost adsorbent. The solvent employed in the modification of bagasse with EDTA is $\mathrm{N}, \mathrm{N}$-Dimethylformamide (DMF), which is a common organic solvent in industrial applications. In addition, DMF has a low cost and good chemical stability, which allows it to be recovered and reused.

In our previous studies, the material synthesized by derivatization of sugarcane bagasse (B) with EDTA (which from this point onward will be referred to as EB) (Fig. 1) was prepared after esterification of B with EDTA dianhydride. The first described applications of this adsorbent were to remove heavy metals such as $\mathrm{Cu}^{2+}, \mathrm{Cd}^{2+}$ and $\mathrm{Pb}^{2+}$ (Karnitz et al., 2007) and to reduce hardness caused by divalent cations such as $\mathrm{Ca}^{2+}$ and $\mathrm{Mg}^{2+}$ (Karnitz et al., 2009) from spiked aqueous solutions. Due to the high efficiency exhibited by EB in removing divalent cations from spiked aqueous solutions, it was used in later studies to remove metals from actual electroplating wastewater (Pereira et al., 2009). In these studies, it was possible to remove $90 \%$ of $\mathrm{Zn}^{2+}$, which proves that the EB has great potential for the removal of metal ions from real world wastewaters.

More recently, our research group has begun a study involving the removal of dyes from aqueous solutions using adsorbent materials originally prepared for the purpose of treating metalcontaminated aqueous solutions. One of these adsorbent materials is sugarcane bagasse modified with succinic anhydride (SCB 2). In the adsorption studies, SCB 2 exhibited great capacity for adsorption of methylene blue (MB) and gentian violet (GV) as model compounds in aqueous solutions (Gusmao et al., 2012). The high maximum adsorption capacities displayed by SCB 2 for adsorption of $\mathrm{MB}$ and $\mathrm{GV}$ in comparison with other adsorbents available in the literature (Table 3 ) motivated our research group to initiate adsorption studies of MB and GV dyes using EB in spiked aqueous solutions. These adsorption studies were performed using different contact times, $\mathrm{pH}$ values, and initial dyes concentrations. The results were evaluated according to four kinetic models and three adsorption models.

\section{Materials and methods}

\subsection{Materials}

Sugarcane bagasse was collected from local alcohol and sugar industries in the city of Ouro Preto, Minas Gerais, Brazil. Cationic dyes, methylene blue (MB, $\mathrm{C}_{16} \mathrm{H}_{18} \mathrm{~N}_{3} \mathrm{SCl}, \lambda_{\max }=584 \mathrm{~nm}$, $\mathrm{MM}=319.85 \mathrm{~g} / \mathrm{mol})$ and gentian violet $\left(\mathrm{GV}, \mathrm{C}_{25} \mathrm{H}_{30} \mathrm{~N}_{3} \mathrm{Cl}\right.$, $\lambda_{\max }=661 \mathrm{~nm}, \mathrm{MM}=407.98 \mathrm{~g} / \mathrm{mol}$ ) (see Fig. 1), were purchased from Synth (Brazil) and used without further purification. EDTA disodium salt and acetic anhydride were also purchased from Synth (Brazil) and used without purification. Pyridine was purchased from Vetec (Brazil). It was left under reflux overnight with $\mathrm{NaOH}$ and then distilled. $\mathrm{N}, \mathrm{N}$-Dimethylformamide (DMF) was purchased from Tedia and distilled at reduced pressure before being used.

\subsection{Sugarcane bagasse preparation}

First, sugarcane bagasse was dried under sun light for $6 \mathrm{~h}$. The bagasse stalks were manually broken to reduce their length and then dried in an oven at $90^{\circ} \mathrm{C}$ for $24 \mathrm{~h}$. Afterward, they were pulverized in a mill with tungsten rings. The powder was sifted in a four-sieve system $(10,60,100$ and 200 mesh). The fraction from the 100-200 mesh was collected and washed first with hot distilled water at $60-70{ }^{\circ} \mathrm{C}$ to eliminate residual sugars and then with $95 \% \mathrm{EtOH}$ and dried at $90{ }^{\circ} \mathrm{C}$ in an oven. Finally, this fraction was washed in a Soxhlet apparatus with hexane-ethanol $(1: 1, \mathrm{v}: \mathrm{v})$ for $4 \mathrm{~h}$, then dried at $90^{\circ} \mathrm{C}$ in an oven to remove organic solvents and stored in a desiccator prior to use.

\subsection{Preparation of EDTA dianhydride (EDTAD)}

The EDTA dianhydride was prepared using the methodology described by Karnitz et al. (2007), using EDTA disodium salt and the acetic anhydride. EDTA disodium (50.0 g) was dissolved in a $1000 \mathrm{~mL}$ beaker containing $500 \mathrm{~mL}$ of distilled water. Concentrated $\mathrm{HCl}$ was added drop by drop until precipitation of $\mathrm{H}_{4}$ EDTA occurred. The precipitate was vacuum filtered and rinsed in $95 \% \mathrm{EtOH}$, 99\% diethyl ether and subsequently dried in an oven for $2 \mathrm{~h}$ at $105{ }^{\circ} \mathrm{C}$ and cooled in a desiccator prior to use.

For the preparation of EDTA dianhydride, $18.0 \mathrm{~g}$ of $\mathrm{H}_{4}$ EDTA was suspended in $31 \mathrm{~mL}$ of anhydrous pyridine in a $250 \mathrm{~mL}$ roundbottom flask equipped with a reflux condenser, and $24 \mathrm{~mL}$ of acetic anhydride was added to the suspension. The mixture was heated and kept stirring at $65^{\circ} \mathrm{C}$ for $24 \mathrm{~h}$. After this reaction time, the solid (EDTA dianhydride) was vacuum filtered, rinsed in diethyl ether and stored in a desiccator under reduced pressure prior to use. 


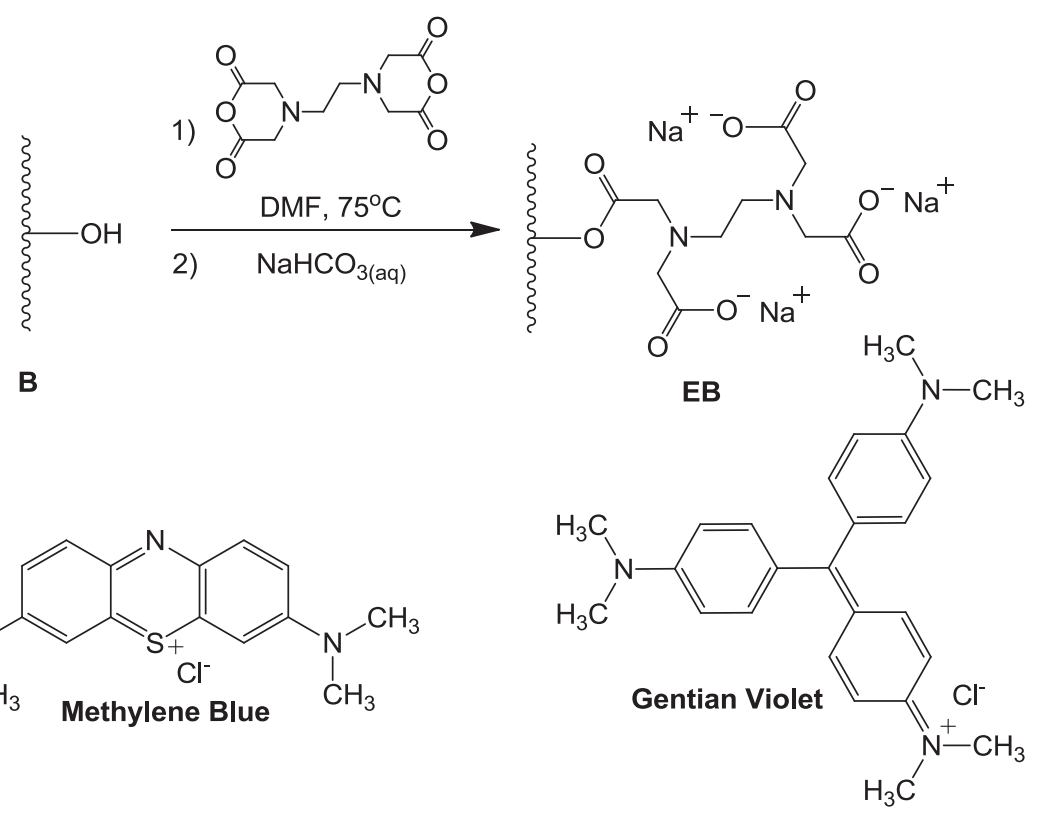

Fig. 1. The EB synthesis route and structures of methylene blue (MB) and gentian violet (GV) dyes.

\subsection{Functionalization of sugarcane bagasse with EDTAD: synthesis of $E B$}

Functionalization of the sugarcane bagasse with EDTAD was performed according to the methodology described by Karnitz et al. (2007). Sugarcane bagasse (B) ( $3 \mathrm{~g}$ ) and EDTAD (9 g) were added to a $250 \mathrm{~mL}$ round-bottom flask with $126 \mathrm{~mL}$ of anhydrous DMF. The suspension was heated at $75^{\circ} \mathrm{C}$ for $24 \mathrm{~h}$ under gentle stirring. At the end of the reaction, the suspension was vacuum filtered using a sintered glass funnel and rinsed consecutively in DMF, distilled water, a saturated solution of sodium bicarbonate, distilled water and finally with 95\% EtOH. Afterward, the sugarcane bagasse modified with EDTAD (EB) was dried in an oven at $100{ }^{\circ} \mathrm{C}$ for $1 \mathrm{~h}$ and stored in a desiccator prior to use.

\subsection{Characterization of the $E B$}

The EB was characterized by weight gain, FTIR and elemental analysis. The $\mathrm{KBr}$ pellet was prepared by mixing $1 \mathrm{mg}$ of the EB with $100 \mathrm{mg}$ of KBr. FTIR analysis was carried out in a Nicolet Impact model 410 spectrometer. The FTIR spectrum was recorded from 4000 to $400 \mathrm{~cm}^{-1}$ with a resolution of $4 \mathrm{~cm}^{-1}$ and 32 scans per sample. The elemental analysis of $\mathrm{C}, \mathrm{H}, \mathrm{N}$ and $\mathrm{O}$ was made on an instrument of elemental analysis, a CHNS/O Perkin Elmer 2400 analyzer Series II.

\section{6. $p H$ of point of zero charge $\left(p H_{Z P C}\right)$}

The $\mathrm{pH}$ of point of zero charge $\left(\mathrm{pH}_{\mathrm{ZPC}}\right)$ for $\mathrm{EB}$ was determined using the mass titration method as described by Noh and Schwarz (1990). Sodium nitrate $\left(\mathrm{NaNO}_{3}\right)$ solutions with $\mathrm{pH}$ values of 3, 6, and 9 were prepared using $0.1 \mathrm{~mol} / \mathrm{L} \mathrm{HNO}_{3}$ and $0.1 \mathrm{~mol} / \mathrm{L} \mathrm{NaOH}$. Six aliquots of $20.0 \mathrm{~mL}$ each were taken from the solution and transferred to $50 \mathrm{~mL}$ Erlenmeyer flasks. Different amounts of EB were then added to the Erlenmeyer flasks to give suspensions of 0.05, 0.1, 0.5, 1.5 , and $10 \%$. The equilibrium $\mathrm{pH}$ was measured after $24 \mathrm{~h}$ of shaking.

\subsection{BET surface area and pore size}

The experiments to obtain the surface area, volume and width of the EB micropores were carried out on a NOVA ${ }^{\circledR}$ Surface Area Analyzer model 1000, Quantachrome Instrument.

\subsection{Adsorption experiments}

EB was used for dye ( $\mathrm{MB}$ and $\mathrm{GV}$ ) adsorption in aqueous solutions using a batch adsorption process. All the adsorption experiments were performed at $25{ }^{\circ} \mathrm{C}$. The adsorption data were modeled by several kinetic and isotherm models.

\subsubsection{Kinetic study of adsorption of $M B$ and $G V$ onto $E B$}

Samples of EB $(20 \mathrm{mg})$ were weighed and added to $250 \mathrm{~mL}$ Erlenmeyer flasks with $100.0 \mathrm{~mL}$ of dye solution, $200 \mathrm{mg} / \mathrm{L}$ for $\mathrm{MB}$ or $450 \mathrm{mg} / \mathrm{L}$ for GV. The Erlenmeyer flasks were shaken at constant speed ( $150 \mathrm{rpm}$ ) with $\mathrm{pH}$ between 7.0 and 8.0 at $25^{\circ} \mathrm{C}$ for different time intervals $(10,20,30,45,60,90,120,180,360,540,720$, and $1440 \mathrm{~min}$ ). At the end of each adsorption time, samples were subjected to centrifugation (centrifugal Excelsa ${ }^{\circledR}$ II, Mod 206 BL) at $3600 \mathrm{rpm}$ for $20 \mathrm{~min}$ to separate the phases. The residual concentrations of MB and GV in the supernatant phase were determined by UV-Vis spectrophotometry (Biospectro, SP220) at wavelengths of 661 and $584 \mathrm{~nm}$, respectively. The amount of dye adsorbed onto EB in each period of time was calculated using the following equation.

$q_{t}=\left[\frac{\left(C_{i}-C_{f}\right) \times V}{w}\right]$

where $q_{t}$ is the amount of dye adsorbed ( $\mathrm{mg}$ ) per weight of EB (g) at time $t, V$ the volume of dye solution (L), $C_{i}$ the initial concentration of dye $(\mathrm{mg} / \mathrm{L}), C_{f}$ the concentration of dye at time $t(\mathrm{mg} / \mathrm{L})$ and $w$ the weight of the EB $(\mathrm{g})$.

\subsubsection{Adsorption as a function of $\mathrm{pH}$}

In order to evaluate the effect of $\mathrm{pH}$ on the adsorption of dyes onto EB, $20.0 \mathrm{mg}$ samples of EB were added to $250 \mathrm{~mL}$ Erlenmeyer flasks with $100.0 \mathrm{~mL}$ of dye solution of known concentration, $200 \mathrm{mg} / \mathrm{L}$ and $300 \mathrm{mg} / \mathrm{L}$ for MB and GV, respectively. The $\mathrm{pH}$ of each mixture was adjusted to values between 2 and 10 by adding drops of $\mathrm{HCl}$ and $\mathrm{NaOH}$ solutions $(0.01-0.1 \mathrm{~mol} / \mathrm{L})$. The Erlenmeyer flaks were kept stirring until a point of equilibrium was reached $(10 \mathrm{~h}$ and $15 \mathrm{~h}$ for $\mathrm{MB}$ and $\mathrm{GV}$, respectively). Throughout the experiments the $\mathrm{pH}$ was checked and if any variation took place, 
the $\mathrm{pH}$ was corrected to the initial value chosen for each set of experiments using $\mathrm{HCl}$ and/or $\mathrm{NaOH}$ solutions $(0.01-0.1 \mathrm{~mol} / \mathrm{L})$. After shaking, the samples were subjected to centrifugation at $3600 \mathrm{rpm}$ for $20 \mathrm{~min}$ to separate the phases and the final concentration of each dye solution was determined by UV-Vis spectrophotometry. The amount of dye adsorbed onto EB at each $\mathrm{pH}$ was calculated according to Eq. (1).

\subsubsection{Adsorption isotherms}

Experiments with dyes (MB and GV) and EB were performed to determine the adsorption isotherms. Samples of EB, $20.0 \mathrm{mg}$, were added to $250 \mathrm{~mL}$ Erlenmeyer flasks containing $100.0 \mathrm{~mL}$ of dye solutions of known concentration, varying from 50 to $300 \mathrm{mg} / \mathrm{L}$ for $\mathrm{MB}$ and from 150 to $400 \mathrm{mg} / \mathrm{L}$ for GV. The experiments were performed at $\mathrm{pH} 8.0$ for both dyes, for the time required to reach the equilibrium. The $\mathrm{pH}$ was adjusted to the optimum value for adsorption using drops of $\mathrm{HCl}$ and $\mathrm{NaOH}$ solutions in concentrations ranging from 0.01 to $0.1 \mathrm{~mol} / \mathrm{L}$. The equilibrium times used in the experiments were obtained from kinetic studies ( $10 \mathrm{~h}$ and $15 \mathrm{~h}$ for $\mathrm{MB}$ and $\mathrm{GV}$, respectively). The amount of dye adsorbed at equilibrium, $q_{e}(\mathrm{mg} / \mathrm{g})$ was calculated using the following equation.

$q_{e}=\frac{\left(C_{i}-C_{e}\right) \times V}{w}$

where $C_{i}$ and $C_{e}$ are the concentrations of the dye in the liquid phase ( $\mathrm{mg} / \mathrm{L}$ ) at time 0 and $t$ (equilibrium), respectively, $V$ the volume of dye solution (L), and $w$ the weight of EB (g).

\subsection{Free energy of adsorption}

According to Liu (2009), the Gibbs free energy change $\left(\Delta G^{\circ}\right)$ indicates the degree of spontaneity of an adsorption process. The $\Delta G^{\circ}$ of adsorption is calculated as follows:

$\Delta G^{\circ}=-R T \ln K_{a}$

where $R$ is the gas constant $8.314 \mathrm{~J} / \mathrm{K} \mathrm{mol}, T(\mathrm{~K})$ the absolute temperature, and $K_{a}$ is the thermodynamic equilibrium constant without units. The Langmuir equilibrium constant has been often used for calculation of $\Delta G^{\circ}$ using Eq. (3) in adsorption studies (Liu, 2009). However, it should be pointed out that the thermodynamic equilibrium constant in Eq. (3) is unitless, whilst the Langmuir constant has units of $\mathrm{L} / \mathrm{mol}$. Liu (2009) has demonstrated in detail that the relationship between the Langmuir equilibrium constant, $K_{L}$, and the thermodynamic equilibrium constant, $K_{a}$, can be given by Eq. (4).

$K_{a}=\left[\frac{K_{L}}{\gamma_{e}} \times(1 \mathrm{~mol} / \mathrm{L})\right]$

where $\gamma_{e}$ is a function of the ionic strength $\left(I_{e}\right)\left(\log \gamma_{e}=-A z^{2} I_{e}\right)$ of the solute at adsorption equilibrium and the charge carried by the solute ( $z$ ) (Debye-Hückel law). According to Liu (2009), in the case of neutral adsorbates or adsorbates with weak charges, Eq. (4) turns to:

$\Delta G^{\circ} \approx-R T \ln \left[K_{L} \times(1 \mathrm{~mol} / \mathrm{L})\right]=-R T \ln K_{L}$

This approach implies that for adsorbates with weak charge, e.g., organic compounds such as dye molecules, the Langmuir equilibrium constant with units of $\mathrm{L} / \mathrm{mol}$ can be reasonably used for determination of $\Delta G^{\circ}$. A detailed reading of Liu's discussion is strongly recommended by authors to avoid erroneous use of this approach in the calculation of $\Delta G^{\circ}$.

\section{Results and discussion}

\subsection{Synthesis and characterization}

EB was prepared as described in Section 2.4 and as depicted in Fig. 1, from which a product was obtained with a weight gain of $50.7 \%$ (Table 1 ). The nitrogen content was determined by elemental analysis and this information permitted calculation of the quantity of EDTA units introduced into the bagasse matrix after esterification of the hydroxyl groups.

As can be seen in Table 1, there was a considerable increase in nitrogen content after modification with EDTAD, which was also accompanied by significant weight gain, indicating a successful reaction and the incorporation of amine functions in the modified material (EB).

\subsection{FTIR spectroscopy}

The spectra of bagasse before (B) and after modification with EDTAD (EB) are shown in Fig. 2. When comparing the infrared spectrum of EB to the spectrum of unmodified bagasse, the appearance of strong bands at $1741 \mathrm{~cm}^{-1}$ can be attributed to axial deformation of the ester bond $(-\mathrm{O}-\mathrm{C}=\mathrm{O})$, and bands at 1633 and $1406 \mathrm{~cm}^{-1}$ are attributed to asymmetric and symmetric axial deformations of carboxylate $\left(-\mathrm{COO}^{-}\right)$. These bands confirmed the introduction of EDTA dianhydride via formation of ester linkages with consequent release of carboxylate functions (Karnitz et al., 2007).

\subsection{Surface area, volume and width of the micropores}

By modeling the adsorption of gases by porous materials, it is possible to evaluate various characteristics of the porous solids, such as surface area, pore volume and width. Obtaining these parameters is important since they are related to the sites available for adsorption. The surface area, average pore volume and average pore diameter were determined and found to be $1.458 \mathrm{~m}^{2} / \mathrm{g}$, $0.00394 \mathrm{~cm}^{3} / \mathrm{kg}$ and $7.810 \mathrm{~nm}$, respectively. The surface area of EB is small in comparison with other adsorbents such as activated carbons. For instance, Royer et al. (2009) used carbonized pine-fruit shell with a surface area of $702 \mathrm{~m}^{2} / \mathrm{g}$, average pore volume of $0.00023 \mathrm{~cm}^{3} / \mathrm{kg}$, average pore diameter of $5.28 \mathrm{~nm}$, and $\mathrm{pH}_{\mathrm{PZC}}$ of 3.85; with this material they achieved a maximum adsorption capacity of $529 \mathrm{mg} / \mathrm{g}$ of methylene blue. EB has a very low surface area in comparison with carbonized pine-fruit shell; however, the pore diameter of EB is larger than that of carbonized pine-fruit shell. According to Ip et al. (2009), the presence of wider pores favors higher adsorption capacities, especially for larger dye molecules. The surface chemistry of the adsorbents is another important factor that controls the adsorption of adsorbate. According to Ip et al. (2009), surfaces extensively functionalized with carboxylate groups can readily chemisorb cationic dyes.

\subsection{Point of zero charge ( $\left.p H_{P Z C}\right)$}

The point of zero charge $\left(\mathrm{pH}_{\mathrm{PZC}}\right)$ can be used to characterize an adsorbent material, since it indicates the $\mathrm{pH}$ at which the adsorbent material has a net zero surface charge (Reed et al., 2000).

Table 1

Elemental analysis, the quantity of EDTA units introduced on bagasse and weight gain.

\begin{tabular}{llllll}
\hline Material & $\mathrm{C}(\%)$ & $\mathrm{H}(\%)$ & $\mathrm{N}(\%)$ & $\mathrm{C}_{\text {EDTA }}(\mathrm{mmol} / \mathrm{g})$ & Weight gain $(\%)$ \\
\hline B & 43.98 & 6.02 & 0.13 & - & - \\
EB & 39.93 & 4.55 & 2.32 & 0.786 & 50.7 \\
\hline
\end{tabular}




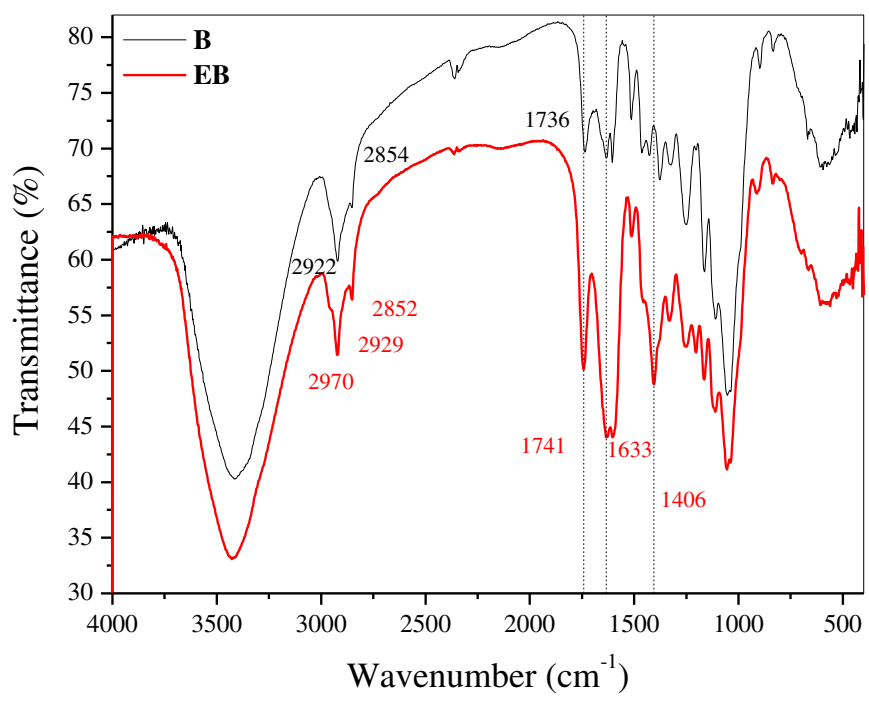

Fig. 2. FTIR spectra of unmodified sugarcane bagasse (B) and modified with EDTA dianhydride (EB).

The adsorbent surface has a net positive charge at $\mathrm{pH}<\mathrm{pH}_{\mathrm{PZC}}$, while at $\mathrm{pH}>\mathrm{pH}_{\mathrm{PZC}}$, the surface has a net negative charge. Therefore, the adsorption of cationic dyes is favored when the $\mathrm{pH}$ is greater than the $\mathrm{pH}_{\mathrm{PZC}}$, while the adsorption of anionic dyes is favored at $\mathrm{pH}$ values lower than the $\mathrm{pH}_{\mathrm{PzC}}$ (Srivastava et al., 2008). The $\mathrm{pH}$ value for the potential of zero charge for EB was 7.5, indicating that when the $\mathrm{pH}$ of the solution is greater than the $\mathrm{pH}_{\mathrm{PZC}}$, the adsorbent has a negatively charged surface that can attract positively charged dyes (MB and GV) (El Qada et al., 2008).

\subsection{Adsorption of methylene blue (MB) and gentian violet (GV) onto $E B$}

\subsubsection{Adsorption kinetic study}

The effect of contact time on adsorption of MB and GV onto EB is shown in Fig. 3. The adsorption of both dyes was rapid in the initial phase and gradually decreased with time until equilibrium was reached. At this point, the amount of dye adsorbed reached a steady state with the amount of dye in solution (Hameed, 2008). The high adsorption rate in the initial period (first $100 \mathrm{~min}$ ) may be due to

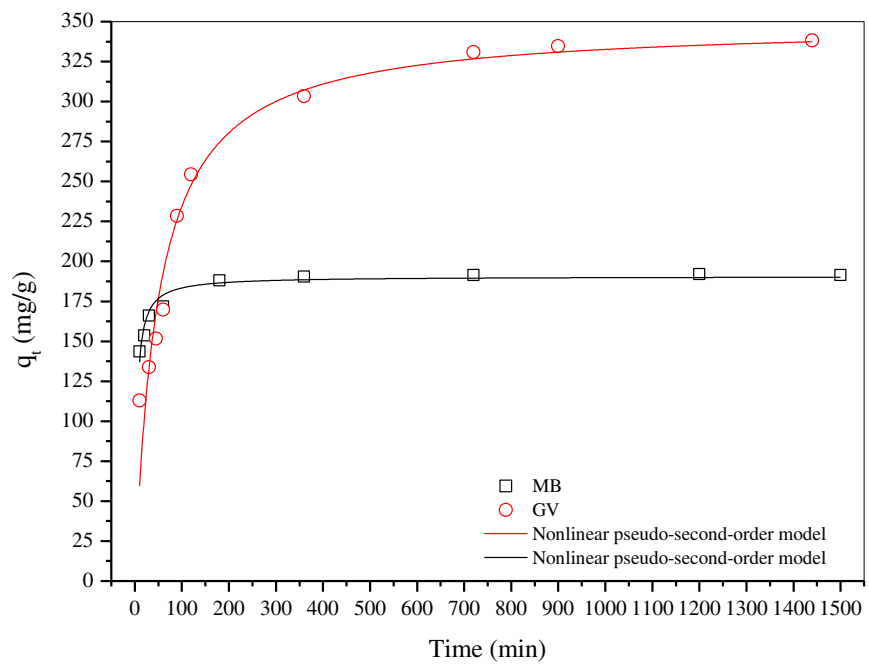

Fig. 3. Evolution of the adsorption of $M B$ and GV dyes onto $E B$ as a function of time. the large number of sites available in the initial phase, resulting in a concentration gradient which tends to increase the adsorption of dyes in the early stages. As time passes, this concentration gradient is reduced due to the accumulation of dye particles on the adsorption sites, leading to a decrease in adsorption rate in the later stages (Uddin et al., 2009).

EDTA is a hexadentate ligand. It has four carboxylate and two amine groups. According to Dean and Lange (1999), $\mathrm{p} K_{a}$ values for its carboxylic groups are equal to $0.0,1.5,2.0$, and 2.69 , and $\mathrm{p} K_{a}$ values for its amine functions are equal to 6.13 and 10.37. When EDTAD is grafted on bagasse via esterification, these values of $\mathrm{p} K_{a}$ probably change, but they may be used to give an idea of the dissociation constants of EDTA molecules bonded on the surface of the bagasse. Above pH 7, all carboxylic groups are deprotonated and one amine group has a non-shared electron pair. This means that the EB surface is negatively charged and the positively charged dye molecules can interact with adsorption sites containing $-\mathrm{COO}^{-}$groups.

The equilibrium times for the adsorption of MB and GV dyes onto EB were found to be 10 and $15 \mathrm{~h}$, respectively. These times were used in the adsorption assays as a function of $\mathrm{pH}$ and in studies of the adsorption isotherms for each dye.

\subsubsection{Adsorption study as a function of $p H$}

The $\mathrm{pH}$ is an important factor controlling the adsorption process. Adsorption of $\mathrm{MB}$ and $\mathrm{GV}$ onto $\mathrm{EB}$ as a function of $\mathrm{pH}$ is shown in Fig. 4. The favorable adsorption in basic $\mathrm{pH}$ can be attributed to the nature of the cationic dyes and the functional groups on the solid support surface $(-\mathrm{COOH})$. In acidic $\mathrm{pH}$, an excess of $\mathrm{H}_{3} \mathrm{O}^{+}$ions decreases the concentration of carboxylate functions $\left(-\mathrm{COO}^{-}\right)$on the adsorbent and increases the concentration of the protonated form $(-\mathrm{COOH})$, causing a decrease in the number of negatively charged sites, which in turn does not favor the adsorption of positively charged dye molecules (Garg et al., 2004). When the pH is increased to values higher than the $\mathrm{pH}_{\mathrm{ZPC}}$ of the $\mathrm{EB}$ (7.5), the number of negatively charged sites on the surface of the adsorbent increases and the amount of MB and GV adsorbed also increases. This can be explained by an electrostatic interaction between the basic dyes and the negatively charged surface of the EB. A similar tendency was observed for MB adsorption onto tea waste, with an optimum pH of 8.0 (Uddin et al., 2009), and pine bark waste, with an optimum pH of 8.5 (Royer et al., 2009). Therefore, the $\mathrm{pH}$ chosen for the study of the adsorption isotherms was 8.0 for all $\mathrm{EB} /$ dye systems.

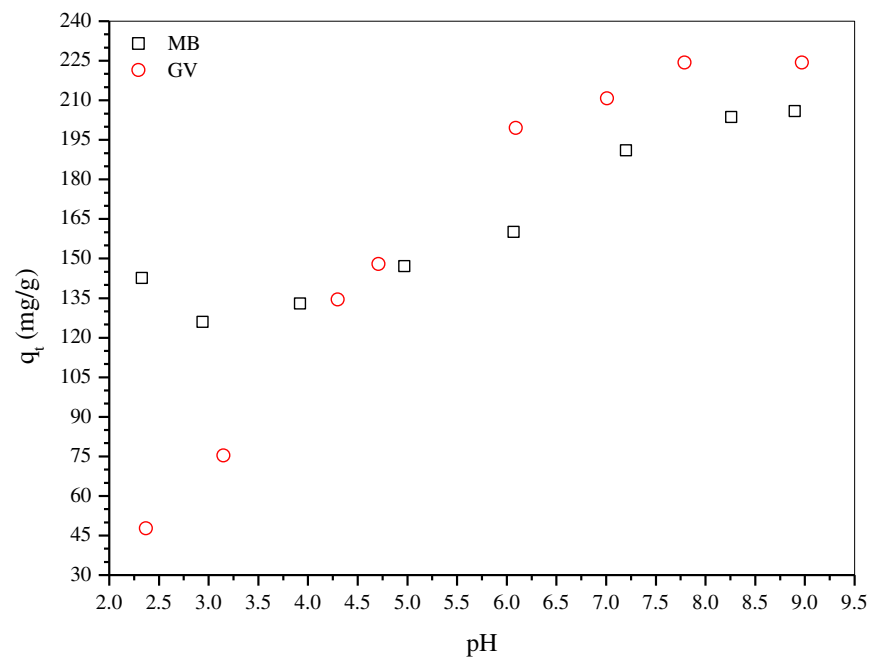

Fig. 4. Evolution of the adsorption of $M B$ and $G V$ dyes onto $E B$ as a function of $\mathrm{pH}$. 


\subsubsection{Adsorption isotherms}

The aim of this study was to understand the dye-adsorbent interaction through the validity of the models and also find parameters that allow for comparison, interpretation and prediction of the adsorption data of the EB (Hamdaoui, 2006). Several isotherm equations are available and three important isotherms were applied to fit the equilibrium data of this study: the Langmuir, Freundlich and Tempkin isotherms.

The Langmuir isotherm theory assumes monolayer coverage of adsorbate on a homogeneous surface of adsorbent (Langmuir, 1918). Graphically, the Langmuir isotherm is characterized by a plateau. Therefore, at equilibrium, the saturation point is reached when adsorption cannot occur. Adsorption occurs at specific sites on the homogeneous surface of the adsorbent. Once a dye molecule occupies a site, there can be no absorption there.

A well-known linear expression for the Langmuir isotherm is shown as follows:

$\frac{C_{e}}{q_{e}}=\frac{1}{Q_{\max } b}+\frac{C_{e}}{Q_{\max }}$

where $Q_{\max }$ and $b$ are the Langmuir constants, representing the maximum adsorption capacity of the solid phase and the constant energy related to the heat of adsorption, respectively, while $C_{e}(\mathrm{mg} /$ $\mathrm{L}$ ) is the concentration of adsorbate in the liquid phase at equilibrium and $q_{e}(\mathrm{mg} / \mathrm{g})$ is the amount of dye adsorbed on the solid phase at equilibrium, respectively.

The values of $Q_{\max }$ and $b$ can be determined from the intercept and the slope of the plot of $C_{e} / q_{e}$ versus $C_{e}$ from the linearized Langmuir equation. One of the essential characteristics of the Langmuir isotherm can be expressed by a separation factor, $R_{L}$, which is defined as follows:

$R_{L}=\frac{1}{1+\left(b C_{i}\right)}$

where $C_{i}$ is the initial concentration of dye. The value of $R_{L}$ indicates whether an isotherm is irreversible $\left(R_{L}=0\right)$, favorable $\left(0<R_{L}<1\right)$, linear $\left(R_{L}=1\right)$ or unfavorable $\left(R_{L}>1\right)$.

The Freundlich isotherm (Freundlich, 1906) is an empirical equation which is applicable to adsorption on heterogeneous surfaces and is not restricted to the formation of a monolayer. It is assumed that an increase in the adsorbate concentration also increases the amount adsorbed on the surface of the adsorbent. The Freundlich isotherm can be expressed in its linear form as follows:

$\ln q_{e}=\ln k_{f}+\frac{1}{n} \ln C_{e}$

where $q_{e}(\mathrm{mg} / \mathrm{g})$ represents the amount of dye adsorbed on the solid phase at equilibrium, $C_{e}(\mathrm{mg} / \mathrm{g})$ is the concentration of adsorbate in the liquid phase at equilibrium, $k_{f}(\mathrm{mg} / \mathrm{g})(\mathrm{L} / \mathrm{mg})^{1 / n}$ indicates the adsorption capacity, and $n$ reflects the intensity of adsorption according to the Freundlich theory, which gives an idea of the favorability of the adsorption. If the value of $1 / n$ falls in the range from 0 to 1 it indicates that the adsorption is favorable. The values of $k_{f}$ and $1 / n$ are calculated from the intercept and slope of the plot of $\ln q_{e}$ versus $\ln C_{e}$.

Tempkin and Pyzhev (1940) considered the effects of some indirect adsorbate/adsorbent interactions in the adsorption isotherm and suggested that due to these interactions the heat of adsorption of all molecules in the layer decreases linearly with coverage. The Tempkin and Pyzhev isotherm can be expressed in its linear form as follows:
$q_{e}=B_{t} \ln A_{t}+B_{t} \ln C_{e}$

where

$B_{t}=\frac{R T}{b}$

The constant $B_{t}(\mathrm{~L} / \mathrm{mg})$ is related to the heat of adsorption, $A_{t}$ $(\mathrm{mg} / \mathrm{L})$ is a constant of the Tempkin isotherm, $b(\mathrm{~J} / \mathrm{mol})$ is the energy constant of the Tempkin isotherm, $R(8.314 \mathrm{~J} / \mathrm{K} \mathrm{mol})$ is the gas constant and $T(\mathrm{~K})$ is the absolute temperature.

Table 2 and Supplementary Table 1 show the values of correlation coefficients and parameters of each isotherm for adsorption of MB and GV dyes onto B and EB. From these data, it was possible to conclude that the Langmuir model best fits the experimental data for both dyes and the adsorbent material, because this model exhibits an $R^{2}$ value closer to unity than the other models. According to the Langmuir model, when a molecule is adsorbed on an adsorbent site, this site becomes unavailable to other molecules. Thus, saturation of sites occurs and a monolayer of dye molecules is formed. The monolayer values $\left(Q_{\max }\right)$ found for the EB adsorbent were $202.43 \mathrm{mg} / \mathrm{g}$ for $\mathrm{MB}$ and $327.87 \mathrm{mg} / \mathrm{g}$ for $\mathrm{GV}$, whilst the $Q_{\max }$ values for unmodified bagasse (B) were $48.50 \mathrm{mg} / \mathrm{g}$ for $\mathrm{MB}$ and $85.62 \mathrm{mg} / \mathrm{g}$ for GV. Comparisons between the $Q_{\max }$ values for B and EB reveal that EB can adsorb 4.17 times more $\mathrm{MB}$ than $\mathrm{B}$ and 3.83 times more GV. Therefore, these results show that the functionalization of $B$ with EDTA dianhydride was effective in improving the adsorption capacity of $\mathrm{B}$, producing an interesting material in terms of its chemical functionality and application. As can be seen, the calculated $R_{L}$ values are between 0 and 1 , indicating that the adsorption of dyes onto $B$ and EB is a favorable process. Fig. 5 and Supplementary Fig. 1 show the linear fit of the Langmuir model to the experimental data of adsorption for MB and GV dyes onto $B$ and EB. As can also be seen in Table 2, the values for free energy change $\left(\Delta G^{\circ}\right)$ for adsorption of MB and GV on EB were found to be -22.50 and $-24.21 \mathrm{~kJ} / \mathrm{mol}$, respectively; whilst, as can be seen in Supplementary Table $1, \Delta G^{\circ}$ values for adsorption of MB and GV on B were -29.16 and $-23.96 \mathrm{~kJ} / \mathrm{mol}$, respectively. These values suggest that the main mechanism of adsorption of MB and GV onto $\mathrm{B}$ and EB is chemisorption.

Table 3 shows the maximum adsorption capacities for MB and GV dyes obtained in this study and those reported in the literature. As can be seen in Table 3, EB showed a greater capacity for adsorption of GV in comparison with MB. Furthermore, when EB is compared to other adsorbent materials, it can be seen that it presents an intermediate capacity for adsorption of MB. Among the adsorbent materials presented in Table 3, two adsorbent materials showed a higher adsorption capacity than EB for adsorption of GV. In addition, SB-EDTAD (Xing et al., 2010) presents a smaller adsorption capacity for MB than EB. A comparison between EB and SB-EDTAD suggests that the methodology used in this study to graft EDTAD on sugarcane bagasse to produce EB was more effective than that used by Xing et al. (2010). However, Xing et al. (2010) did not provide any additional characterization beyond FTIR analysis, such as weight gain and/or elemental analysis, and it was therefore not possible to discern the quantity of EDTA introduced into sugarcane bagasse and the degree of functionalization of the modified material. In comparison with clay minerals such as Kaolin (Ghosh and Bhattacharyya, 2002) and Bentonite (Bellir et al., 2012; Hong et al., 2009) (Table 3), EB exhibited higher adsorption capacity for $\mathrm{MB}$ and GV.

In Table 3, it can be seen that succinylated sugarcane bagasse (SCB 2) exhibited a higher adsorption capacity for MB and GV dyes in comparison with EB. A possible explanation for this difference in adsorption capacities for MB and GV dyes is based on the greater number of chelating functions introduced after chemical 
Table 2

Parameters of the adsorption isotherms for MB and GV dyes onto EB.

\begin{tabular}{|c|c|c|c|c|c|c|c|c|}
\hline \multicolumn{3}{|l|}{ Langmuir } & \multicolumn{3}{|c|}{ Freundlich } & \multicolumn{3}{|l|}{ Tempkin } \\
\hline & MB & GV & & $\mathrm{MB}$ & GV & & MB & GV \\
\hline$Q_{\max }(\mathrm{mg} / \mathrm{g})$ & 202.43 & 327.87 & $K_{f}$ & 3.70 & 183.88 & $A_{t}(\mathrm{mg} / \mathrm{L})$ & 0.013 & 2.79 \\
\hline$Q_{\max }(\mathrm{mmol} / \mathrm{g})$ & 0.71 & 0.88 & & & & & & \\
\hline$b(\mathrm{~L} / \mathrm{mg})$ & 0.0307 & 0.0468 & $n$ & 1.27 & 10.87 & $B_{t}(\mathrm{~L} / \mathrm{mg})$ & 134.62 & 19.67 \\
\hline$b(\mathrm{~L} / \mathrm{mmol})$ & 8.74 & 17.45 & - & - & - & - & - & - \\
\hline$R^{2}$ & 0.9904 & 0.9996 & $R^{2}$ & 0.9411 & 0.8788 & $R^{2}$ & 0.9516 & 0.7919 \\
\hline$R_{L}$ & $0.394-0.098$ & $0.125-0.051$ & - & - & - & - & - & - \\
\hline$\Delta G^{\circ}(\mathrm{kJ} / \mathrm{mol})$ & -22.50 & -24.21 & - & - & - & - & - & - \\
\hline
\end{tabular}

modification of sugarcane bagasse (B) with succinic anhydride (SCB 2, $6.0 \mathrm{mmol} / \mathrm{g},-\mathrm{COOH}$ ) (Gurgel et al., 2008) than with EDTA dianhydride (EB, $2.36 \mathrm{mmol} / \mathrm{g},-\mathrm{COOH})$. In calculating the number of functional groups on EB, it was considered that each unit of EDTA introduced adds three acid carboxylic groups to the solid support (monoesterification). Thus it is expected that, due to its greater number of chelating sites, SCB 2 presents a higher adsorption capacity than EB for the cationic dyes studied; since more chelating sites are available, more cationic molecules can interact by binding to the surface of the adsorbent.

\subsubsection{Adsorption kinetics}

The kinetics of adsorption of a solute onto a solid surface is often complex. The mechanism of adsorption depends on the physical and/or chemical properties of the adsorbent as well as the process of mass transport. To investigate the mechanism of dye adsorption, three kinetic models were considered, pseudo-first-order, pseudosecond-order and the Elovich equation. These models are the most commonly used to describe the adsorption of dyes and other pollutants such as heavy metals onto solid adsorbents.

Lagergren (1898) proposed a method for the analysis of adsorption, namely pseudo-first-order kinetics, whose mathematical equation in linear form is represented below:

$\log \left(q_{e}-q_{t}\right)=\log q_{e}-\frac{k_{1}}{2303} t$

where $q_{e}(\mathrm{mg} / \mathrm{g})$ and $q_{t}(\mathrm{mg} / \mathrm{g})$ are the amounts of adsorbate adsorbed on the surface of the adsorbent at equilibrium and at a given time $t(\mathrm{~min})$ and $k_{1}\left(\mathrm{~min}^{-1}\right)$ is the pseudo-first-order rate constant.

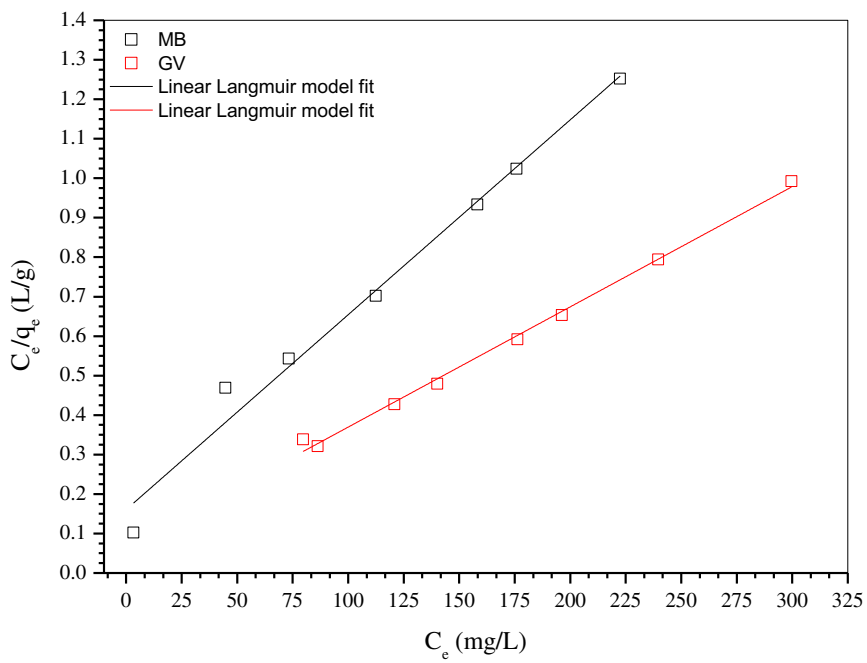

Fig. 5. Langmuir isotherms for the adsorption of MB and GV dyes onto EB.
Ho and McKay (1998) proposed a pseudo-second-order kinetic model for the analysis of adsorption, whose mathematical formulation is shown in its linear form as follows:

$\frac{t}{q_{t}}=\frac{1}{k_{2} q_{e}^{2}}+\frac{1}{q_{e}} t$

where $q_{e}(\mathrm{mg} / \mathrm{g})$ and $q_{t}(\mathrm{mg} / \mathrm{g})$ are the amounts of adsorbate adsorbed on the surface of the adsorbent at equilibrium and at a given time $t(\mathrm{~min})$ and $k_{2}\left(\mathrm{~g} \mathrm{mg}^{-1} \mathrm{~min}^{-1}\right)$ is the pseudo-secondorder rate constant.

The Elovich equation is a kinetic equation related to the chemisorption process (Juang and Chen, 1997). This equation is often validated for systems where the surface of the adsorbent is heterogeneous. The linear form of the Elovich equation is given as follows:

$q_{t}=\frac{1}{\beta} \ln (\alpha \beta)+\frac{1}{\beta} \ln t$

where $\alpha\left(\mathrm{mg} \mathrm{g}^{-1} \mathrm{~min}^{-1}\right)$ is the initial adsorption rate and $\beta\left(\mathrm{g} \mathrm{mg}^{-1}\right)$ is the relationship between the degree of surface coverage and the activation energy involved in the chemisorption.

As can be seen in Table 4, the $R^{2}$ values for the pseudo-secondorder equation are closer to unity than the pseudo-first-order and Elovich equations. Thus, the pseudo-second-order kinetic model describes the adsorption of the dyes more accurately. Moreover, the values of $q_{e, \text { calc }}$ calculated from the pseudo-second-order model

Table 3

Comparison of maximum adsorption capacities for MB and GV dyes with literature data.

\begin{tabular}{|c|c|c|c|}
\hline Adsorbent & Dye & $Q_{\max }(\mathrm{mg} / \mathrm{g})$ & Reference \\
\hline EB & MB & 202.43 & This study \\
\hline $\begin{array}{l}\text { Succinylated sugarcane } \\
\text { bagasse (SCB } 2)\end{array}$ & MB & 478.47 & Gusmao et al. (2012) \\
\hline Brazilian pine-fruit Shell & MB & 252 & Royer et al. (2009) \\
\hline $\begin{array}{l}\text { Carbonaceous Brazilian } \\
\text { pine-fruit shell }\end{array}$ & MB & 529 & Royer et al. (2009) \\
\hline Tea waste & MB & 85.16 & Uddin et al. (2009) \\
\hline Wood sawdust & MB & 120.48 & Ahmad et al. (2009) \\
\hline Esterified wheat straw & MB & 312.50 & Gong et al. (2008) \\
\hline EDTAD-SB & MB & 115.3 & Xing et al. (2010) \\
\hline Kaolin $\left(\mathrm{C}_{6}\right)$ & MB & 20.49 & $\begin{array}{l}\text { Ghosh and Bhattacharyya } \\
\text { (2002) }\end{array}$ \\
\hline Bentonite & MB & 173.0 & Hong et al. (2009) \\
\hline EB & GV & 327.87 & This study \\
\hline $\begin{array}{l}\text { Succinylated sugarcane } \\
\text { bagasse (SCB 2) }\end{array}$ & GV & 1273.16 & Gusmao et al. (2012) \\
\hline Esterified wheat straw & GV & 227.27 & Gong et al. (2008) \\
\hline Wood sawdust & GV & 341 & Chakraborty et al. (2005) \\
\hline Sunflower seed hulls & GV & 92.59 & Hameed (2008) \\
\hline $\begin{array}{l}\text { Activated carbon prepared } \\
\text { from rice husk }\end{array}$ & GV & 64.875 & Mohanty et al. (2006) \\
\hline Bentonite & GV & 108.57 & Bellir et al. (2012) \\
\hline
\end{tabular}


Table 4

Kinetic parameters for the adsorption of MB and GV dyes onto EB.

\begin{tabular}{lll}
\hline & $\mathrm{MB}$ & $\mathrm{GV}$ \\
\hline & $q_{e, \exp }(\mathrm{mg} / \mathrm{g})$ & $q_{e, e x p}(\mathrm{mg} / \mathrm{g})$ \\
& 191.97 & 338.22 \\
Pseudo-first-order model & & \\
$k_{1}\left(\mathrm{~min}^{-1}\right)$ & 0.0038 & 0.0035 \\
$q_{e, \text { calc }}(\mathrm{mg} / \mathrm{g})$ & 18.81 & 173.20 \\
$R^{2}$ & 0.7379 & 0.9513 \\
Pseudo-second-order model & & \\
$k_{2}\left(\mathrm{~g} / \mathrm{mg} \mathrm{min}^{2}\right.$ & 0.0012 & 0.000053 \\
$q_{e, \text { calc }}(\mathrm{mg} / \mathrm{g})$ & 192.31 & 357.14 \\
$R^{2}$ & 1 & 0.9977 \\
Elovich equation & & \\
$\alpha\left(\mathrm{mg}^{2} \mathrm{~g}\right.$ min) & $92.6 \times 10^{5}$ & 31.13 \\
$\beta\left(\mathrm{g} \mathrm{mg}{ }^{-1}\right)$ & 0.11 & 0.018 \\
$R^{2}$ & 0.8913 & 0.9501 \\
\hline
\end{tabular}

were more consistent with the experimental adsorption values $\left(q_{e, \text { exp }}\right)$ than those calculated from the pseudo-first-order model. For the MB dye, the experimental and calculated values were found to be 191.97 and $192.31 \mathrm{mg} / \mathrm{g}$, and 338.22 and $357.14 \mathrm{mg} / \mathrm{g}$ for the GV dye. Fig. 6 shows the linear fit of the pseudo-second-order model to the experimental data of adsorption of MB and GV dyes onto EB.

The pseudo-second-order model is also presented as the best model to describe the adsorption of cationic dyes by other biosorbents, such as in the adsorption of $\mathrm{MB}$ on pineapple waste (Hameed et al., 2009), and of MB and GV onto esterified wheat straw with citric acid (Gong et al., 2008).

\subsection{Adsorption mechanism}

Adsorption kinetics is usually controlled by different mechanisms. The intra-particle diffusion theory (Weber and Morris, 1963) is derived from Fick's law and assumes that the diffusion of the liquid film surrounding the adsorbent is negligible, and intraparticle diffusion is the only rate controlling step of the adsorption process. Eq. (12) shows the mathematical expression used to study this phenomenon.

$q_{t}=k_{i d} \sqrt{t}+C$

where $k_{i d}\left(\mathrm{mg} / \mathrm{g} \min ^{1 / 2}\right)$ is the intra-particle diffusion rate constant and $C$ is the value of the intercept of the plot of $q_{t}$ against $t^{1 / 2}$.

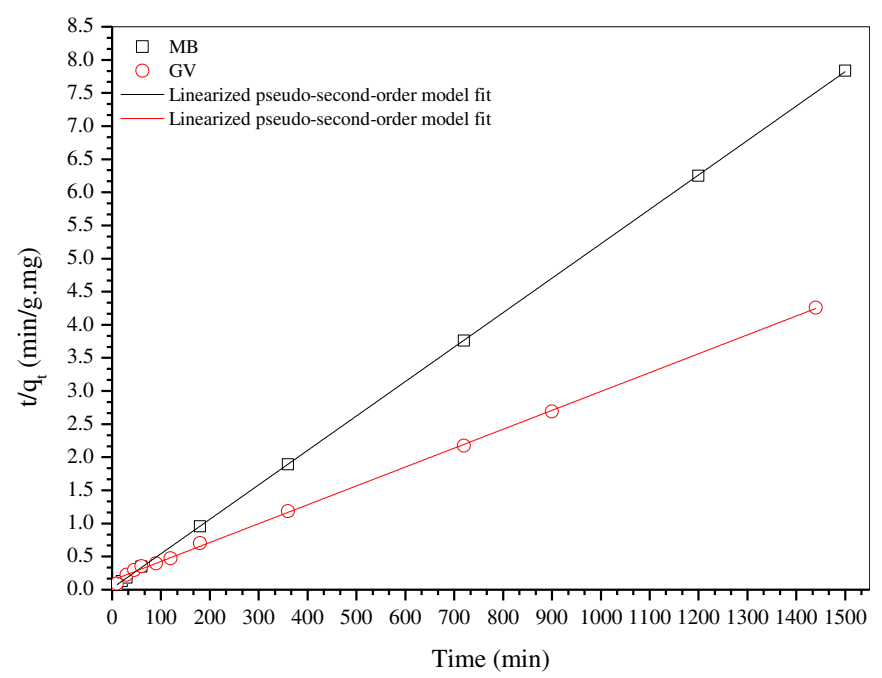

Fig. 6. Pseudo-second-order model fit for the adsorption of MB and GV dyes onto EB.
Table 5

Kinetic parameters of the intra-particle diffusion model for the adsorption of MB and GV dyes onto EB.

\begin{tabular}{|c|c|c|c|c|c|c|}
\hline & \multicolumn{3}{|l|}{ MB } & \multicolumn{3}{|l|}{ GV } \\
\hline & 1st stage & 2nd stage & 3rd stage & 1st stage & 2nd stage & 3rd stage \\
\hline$k_{\text {id }}\left(\mathrm{mg} / \mathrm{g} \mathrm{min}^{1 / 2}\right)$ & 9.55 & 2.79 & 0.13 & 17.56 & 5.71 & 0.61 \\
\hline$C(\mathrm{mg} / \mathrm{g})$ & 112.70 & 150.48 & 187.33 & 44.86 & 183.86 & 315.31 \\
\hline$R^{2}$ & 0.9815 & 0.9994 & 0.7264 & 0.9044 & 0.9518 & 0.9397 \\
\hline
\end{tabular}

If intra-particle diffusion was involved in the adsorption, then a plot of $q_{t}$ against $t^{1 / 2}$ would result in a linear relationship that allows calculation of the value of $k_{\text {id }}$ from the slope. The $C$ intercept values give an idea of the boundary layer thickness, i.e., the larger the intercept, the greater the effect of the boundary layer. The values of $C$ and $k_{i d}$ for the linear segments are shown in Table 5.

Fig. 7 shows plots of $q_{t}$ against $t^{1 / 2}$ for the adsorption processes of $\mathrm{MB}$ and GV dyes onto EB. It is possible, from the plots of $q_{t}$ against $t^{1 / 2}$, to distinguish three phases in the adsorption processes. These results imply the possibility that the adsorption processes involve more than a single kinetic stage. The first stage is an instantaneous adsorption and is probably due to strong electrostatic attraction between the dye and the outer surface of the adsorbent. The second stage is a gradual adsorption stage, which can be attributed to intraparticle diffusion of dye molecules through the pores of the
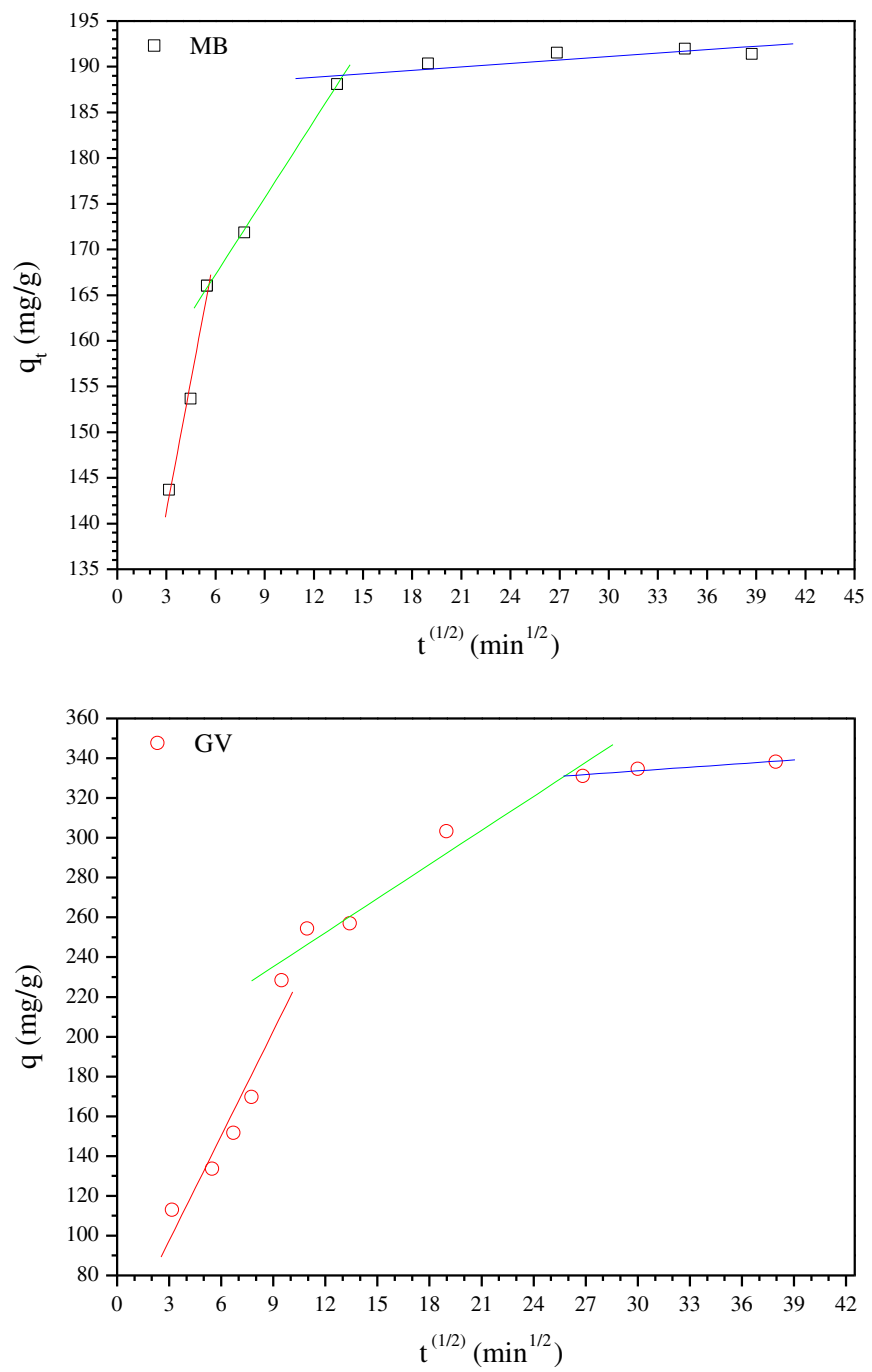

Fig. 7. Intra-particle diffusion model for the adsorption of MB and GV dyes onto EB. 
adsorbent. The final stage corresponds to the equilibrium adsorption, when the dye molecules occupy all the active sites on the adsorbent (Ahmad et al., 2009). The values of $k_{i d}$ were determined from the slopes of the respective linear plots and are presented in Table 5.

The straight lines with higher slope values have larger $k_{i d}$ and consequently a higher adsorption rate per unit time. For the dyes studied (MB and GV), it can be seen in Fig. 7 that as time passes the rate of adsorption decreased, being lower in the equilibrium stage of the system (third step), when all the adsorption sites are already occupied. The values of $C$ were calculated from the intercepts of the straight lines and represent the thickness of the dye adsorbed onto the EB (Table 5).

\section{Conclusions}

The EB adsorbent prepared from sugarcane bagasse proved to be effective for the removal of MB and GV dyes from aqueous solutions by an adsorption process. The FTIR spectrum of EB showed the appearance of strong bands at $1743 \mathrm{~cm}^{-1}, 1631 \mathrm{~cm}^{-1}$ and $1406 \mathrm{~cm}^{-1}$ that confirmed the introduction of EDTA dianhydride into the lignocellulose matrix. Three adsorption kinetic models were tested and the pseudo-second-order model fit the experimental data well. The intra-particle diffusion study yielded three linear regions, which suggested that dye adsorption involves more than one kinetic stage. The Langmuir model fit the experimental data well, suggesting the adsorption occurs in a monolayer. The maximum adsorption capacities for the adsorption of MB and GV dyes onto EB were found to be 202.43 and $327.87 \mathrm{mg} / \mathrm{g}$, respectively.

\section{Acknowledgments}

The authors are grateful to Universidade Federal de Ouro Preto (UFOP), Fundação de Amparo a Pesquisa do Estado de Minas Gerais (FAPEMIG), and Conselho Nacional de Desenvolvimento Científico e Tecnológico (CNPq) for funding this research.

\section{Appendix A. Supplementary data}

Supplementary data related to this article can be found at http://dx.doi.org/10.1016/j.jenvman.2013.01.017.

\section{References}

Ahmad, A., Rafatullah, M., Sulaiman, O., Ibrahim, M.H., Hashim, R., 2009. Scavenging behaviour of meranti sawdust in the removal of methylene blue from aqueous solution. J. Hazard. Mater. 170, 357-365.

Bellir, K., Bouziane, I.S., Boutamine, Z., Lehocine, M.B., Meniai, A.H., 2012. Sorption study of a basic dye "Gentian violet" from aqueous solutions using activated bentonite. Energy Proced. 18, 924-933.

Chakraborty, S., De, S., DasGupta, S., Basu, J.K., 2005. Adsorption study for the removal of a basic dye: experimental and modeling. Chemosphere 58, 1079-1086.

Dean, J.A., Lange, N.A., 1999. Handbook of Chemistry. McGraw-Hill.

El Qada, E.N., Allen, S.J., Walker, G.A., 2008. Adsorption of basic dyes from aqueous solution onto activated carbons. Chem. Eng. J. 135, 174-184.

Forgacs, E., Cserhati, T., Oros, G., 2004. Removal of synthetic dyes from wastewaters: a review. Environ. Int. 30, 953-971.

Freundlich, H., 1906. Concerning adsorption in solutions. Z. Phys. Chem. - Stoch. Ve. $57,385-470$

Garg, V.K., Kumar, R., Gupta, R., 2004. Removal of malachite green dye from aqueous solution by adsorption using agro-industry waste: a case study of Prosopis cineraria. Dyes Pigm. 62, 1-10.

Ghosh, D., Bhattacharyya, K.G., 2002. Adsorption of methylene blue on kaolinite. Appl. Clay Sci. 20, 295-300.

Gong, R.M., Zhu, S.X., Zhang, D.M., Chen, J., Ni, S.J., Guan, R., 2008. Adsorption behavior of cationic dyes on citric acid esterifying wheat straw: kinetic and thermodynamic profile. Desalination 230, 220-228.
Gupta, V.K., Mittal, A., Krishnan, L., Gajbe, V., 2004. Adsorption kinetics and column operations for the removal and recovery of malachite green from wastewater using bottom ash. Sep. Purif. Technol. 40, 87-96.

Gurgel, L.V.A., de Freitas, R.P., Gil, L.F., 2008. Adsorption of $\mathrm{Cu}(\mathrm{II}), \mathrm{Cd}(\mathrm{II})$, and $\mathrm{Pb}(\mathrm{II})$ from aqueous single metal solutions by sugarcane bagasse and mercerized sugarcane bagasse chemically modified with succinic anhydride. Carbohydr. Polym. 74, 922-929.

Gusmao, K.A.G., Gurgel, L.V.A., Melo, T.M.S., Gil, L.F., 2012. Application of succinylated sugarcane bagasse as adsorbent to remove methylene blue and gentian violet from aqueous solutions - kinetic and equilibrium studies. Dyes Pigm. 92, 967-974.

Hamdaoui, O., 2006. Batch study of liquid-phase adsorption of methylene blue using cedar sawdust and crushed brick. J. Hazard. Mater. 135, 264-273.

Hameed, B.H., 2008. Equilibrium and kinetic studies of methyl violet sorption by agricultural waste. J. Hazard. Mater. 154, 204-212.

Hameed, B.H., 2009. Spent tea leaves: a new non-conventional and low-cost adsorbent for removal of basic dye from aqueous solutions. J. Hazard. Mater. $161,753-759$

Hameed, B.H., Krishni, R.R., Sata, S.A., 2009. A novel agricultural waste adsorbent for the removal of cationic dye from aqueous solutions. J. Hazard. Mater. 162, 305-311.

Ho, Y.S., McKay, G., 1998. Kinetic models for the sorption of dye from aqueous solution by wood. Process Saf. Environ. Prot. 76, 183-191.

Ho, Y.S., Chiu, W.T., Wang, C.C., 2005. Regression analysis for the sorption isotherms of basic dyes on sugarcane dust. Bioresour. Technol. 96, 1285-1291.

Hong, S., Wen, C., He, J., Gan, F.X., Ho, Y.S., 2009. Adsorption thermodynamics of Methylene Blue onto bentonite. J. Hazard. Mater. 167, 630-633.

Ip, A.W.M., Barford, J.P., Mckay, G., 2009. Reactive Black dye adsorption/desorption onto different adsorbents: effect of salt, surface chemistry, pore size and surface area. J. Colloid Interf. Sci. 337, 32-38.

Juang, R.S., Chen, M.L., 1997. Application of the Elovich equation to the kinetics of metal sorption with solvent-impregnated resins. Ind. Eng. Chem. Res. 36, 813-820.

Karnitz, O., Gurgel, L.V.A., de Melo, J.C.P., Botaro, V.R., Melo, T.M.S., Gil, R.P.D.F., Gil, L.F., 2007. Adsorption of heavy metal ion from aqueous single metal solution by chemically modified sugarcane bagasse. Bioresour. Technol. 98, 1291-1297.

Karnitz, O., Gurgel, L.V.A., de Freitas, R.P., Gil, L.F., 2009. Adsorption of Cu(II), Cd(II), and $\mathrm{Pb}(\mathrm{II})$ from aqueous single metal solutions by mercerized cellulose and mercerized sugarcane bagasse chemically modified with EDTA dianhydride (EDTAD). Carbohydr. Polym. 77, 643-650.

Lagergren, S.Y., 1898. Zur Theorie der sogenannten Adsorption gelöster Stoffe, Kungliga Svenska Vetenskapsakademiens. Handlingar 24, 1-39.

Langmuir, I., 1918. The adsorption of gases on plane surfaces of glass, mica and platinum. J. Am. Chem. Soc. 40, 1361-1403.

Lata, H., Garg, V.K., Gupta, R.K., 2008. Adsorptive removal of basic dye by chemically activated Parthenium biomass: equilibrium and kinetic modeling. Desalination $219,250-261$.

Liu, Y., 2009. Is the free energy change of adsorption correctly calculated? J. Chem. Eng. Data 54, 1981-1985.

Mohanty, K., Naidu, J.T., Meikap, B.C., Biswas, M.N., 2006. Removal of crystal violet from wastewater by activated carbons prepared from rice husk. Ind. Eng. Chem. Res. 45, 5165-5171.

Navarro, R.R., Sumi, K., Fujii, N., Matsumura, M., 1996. Mercury removal from wastewater using porous cellulose carrier modified with polyethyleneimine. Water Res. 30, 2488-2494.

Noh, J.S., Schwarz, J.A., 1990. Effect of $\mathrm{HNO}_{3}$ treatment on the surface-acidity of activated carbons. Carbon 28, 675-682.

Pereira, F.V., Gurgel, L.V.A., de Aquino, S.F., Gil, L.F., 2009. Removal of $\mathrm{Zn}(2+)$ from electroplating wastewater using modified wood sawdust and sugarcane bagasse. J. Environ. Eng. - ASCE 135, 341-350.

Reed, B.E., Vaughan, R., Jiang, L.Q., 2000. As(III), As(V), Hg, and Pb removal by Feoxide impregnated activated carbon. J Environ Eng-Asce 126, 869-873.

Royer, B., Cardoso, N.F., Lima, E.C., Vaghetti, J.C.P., Simon, N.M., Calvete, T., Veses, R.C., 2009. Applications of Brazilian pine-fruit shell in natural and carbonized forms as adsorbents to removal of methylene blue from aqueous solutions - kinetic and equilibrium study. J. Hazard. Mater. 164, 1213-1222.

Srivastava, V.C., Mall, I.D., Mishra, I.M., 2008. Adsorption of toxic metal ions onto activated carbon - study of sorption behaviour through characterization and kinetics. Chem. Eng. Process. 47, 1275-1286.

Sun, Q.Y., Yang, L.Z., 2003. The adsorption of basic dyes from aqueous solution on modified peat-resin particle. Water Res. 37, 1535-1544.

Tempkin, M., Pyzhev, V., 1940. Kinetics of ammonia synthesis on promoted iron catalysts. Acta Physicochim. URSS 12, 327-356.

Uddin, M.T., Islam, M.A., Mahmud, S., Rukanuzzaman, M., 2009. Adsorptive removal of methylene blue by tea waste. J. Hazard. Mater. 164, 53-60.

Weber, W.J., Morris, J.C., 1963. Kinetics of adsorption on carbon from solution. J. Sanitary Eng. Division 89, 31-60.

Xiao, B., Sun, X.F., Sun, R.C., 2001. The chemical modification of lignins with succinic anhydride in aqueous systems. Polym. Degrad. Stab. 71, 223-231.

Xing, Y., Deng, D.H., 2009. Enhanced adsorption of malachite green by EDTADmodified sugarcane bagasse. Separat. Sci. Technol. 44, 2117-2131.

Xing, Y., Liu, D., Zhang, L.P., 2010. Enhanced adsorption of Methylene Blue by EDTAD-modified sugarcane bagasse and photocatalytic regeneration of the adsorbent. Desalination 259, 187-191. 